\title{
Successful maternal and fetal outcome in an uncorrected case of tetralogy of fallot
}

\author{
Aditya R. Nimbkar*, Shruti A. Panchbudhe, Prasad Y. Deshmukh, Arun H. Nayak
}

Department of Obstetrics and Gynecology, Lokmanya Tilak Municipal General Hospital and Medical College, Mumbai, Maharashtra, India

Received: 21 October 2021

Accepted: 12 November 2021

\section{*Correspondence:}

Dr. Aditya R. Nimbkar,

E-mail: nimbkaradi17@gmail.com

Copyright: ( ) the author(s), publisher and licensee Medip Academy. This is an open-access article distributed under the terms of the Creative Commons Attribution Non-Commercial License, which permits unrestricted non-commercial use, distribution, and reproduction in any medium, provided the original work is properly cited.

\begin{abstract}
Tetralogy of Fallot (ToF) is the most common congenital heart defect which is associated with systemic cyanosis. Pregnancy and delivery cause dramatic alterations in cardiovascular physiology and pregnancy in women with unrepaired TOF may have a worsening in right to left shunt with an increase of the cyanosis. This possesses an elevated risk of maternal and foetal morbidity and even mortality. We report and discuss a case of a 24 years old Primigravida with uncorrected ToF. A multidisciplinary team was involved in the management of the case with the aim to minimize maternal and foetal complications. The target of the management was to perform adequate maternal surveillance by maintaining an adequate oxygen saturation and good haemoglobin levels and perform timely foetal surveillance tests in the form of Obstetric doppler. A caesarean section was performed at 35 weeks and 5 days of gestation without any maternal or fetal complications. Without optimal obstetrical or medical management, prognosis of pregnancy in patient with uncorrected ToF is poor.
\end{abstract}

Keywords: Tetralogy of fallot, Uncorrected, Pregnancy, Cyanotic congenital heart disease

\section{INTRODUCTION}

Tetralogy of Fallot (ToF) is the commonest form of cyanotic congenital heart disease. After 1 year of age the overall incidence approaches $10 \%$ of all congenital heart disease. ${ }^{1}$ It is a right to left shunt defect that causes increased in deoxygenated blood in the circulation resulting in decreased $\mathrm{SpO} 2$ levels. In the today's era of ultrasonography, majority of these patients are diagnosed in intrauterine life leading to their early identification and treatment in the first year of their life. Only $24 \%$ of patients with uncorrected TOF survive up to 10 years of age and a case of an uncorrected TOF in pregnancy is a rare occurrence.

Tetralogy of Fallot is a congenital heart disease with four components which includes right ventricular outflow tract obstruction, right ventricular hypertrophy, large ventricular septal defect and overriding of aorta. It is caused embryologically due to antero-cephalad deviation of the developing ventricular outflow septum or it's fibrous remnant, which if it fails to muscularise causes the ventricular septal hole defect. Ventricular hypertrophy is due to the hypertrophy of septoparietal trabeculations. The overriding of the aorta is because of the misalignment and displacement of the deviated septum into the right ventricle. The deviation of septum and hypertrophy of trabeculations causes right ventricular outflow tract obstruction which is accentuated by catecholamines and fluid depletion states. This causes the patient to have hyper cyanotic/Tet spells that are alleviated by squatting to increase systematic vascular resistance

Natural survival without performing any corrective procedure into the fourth decade is extremely rare which is only about $3 \%$ but there is a tendency of increasing number of women with cyanotic congenital heart disease living up to 3 to 4 decades and becoming pregnant. ${ }^{2,3}$ Due 
to significant physiological adaptation and changes, pregnancy and delivery process is troublesome for mostly unhealthy women, including those with uncorrected ToF. Advances in reparative cardiovascular surgery has improved the prognosis of the women with corrected ToF and they now survive until the childbearing age $(94 \%$ up to the age of 20 years and $85 \%$ up to the age of 36 years). ${ }^{4}$ Maternal morbidity in ToF patients constitutes $62.5 \%$ and causes include arrythmias, heart failure, infective endocarditis etc and mortality constitutes $10 \%$. It also has significant effects on foetal outcome like miscarriage, foetal growth restriction, foetal loss and thromboembolism, secondary to the reactive polycythaemia. ${ }^{5,6}$ Maternal risk assessment in women with cardiovascular disease should be performed according to the modified World Health Organization (WHO) classification and in accordance with the WHO classification, the repaired TOF is ranked in class II and the cyanotic unrepaired heart diseases in class III.

\section{CASE REPORT}

A 24 years old female was referred to antenatal out patient department of our tertiary care hospital at 6 months of gestation with a diagnosed case of Uncorrected Tetralogy of Fallot for antenatal registration and further evaluation and management. Patient was Primigravida and had chief complaints of worsening difficulty of breathing on unaccustomed activity and noticed bluish discoloration of upper limb digits from last 7 days prior to admission. She consulted a private practitioner who advised 2D echocardiogram for her and was subsequently diagnosed to have uncorrected ToF. Patient's complaints improved at rest and worsened by activities. There was however no orthopnea, paroxysmal nocturnal dyspnea, cough, wheezing sound during breathing, and edema. Patient did not give any history of Tet spells or episodes of breathlessness since childhood nor had any of them during her ward admission. Patient was admitted to the antenatal ward for safe confinement. Patient had no other significant medical or surgical history.

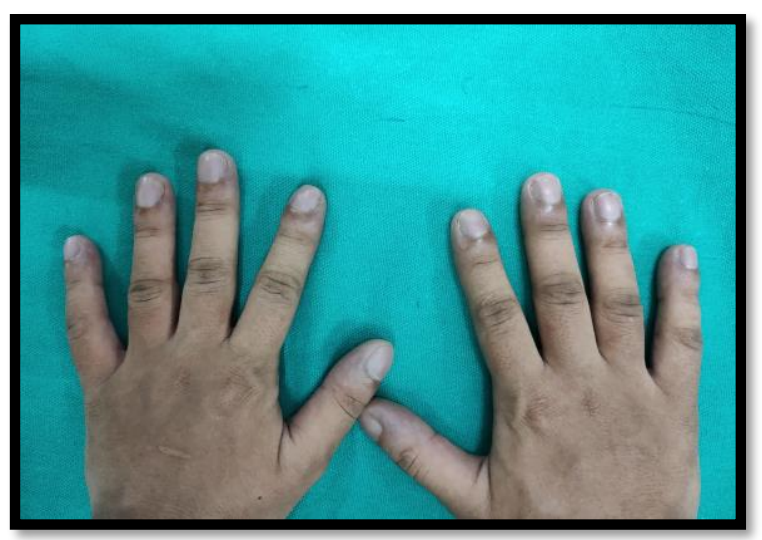

Figure 1: Peripheral cyanosis.

On general examination she was fully conscious, afebrile, with pulse rate - 90/ minute, regular, normo-volaemic, blood pressure - 120/80 $\mathrm{mm}$ of $\mathrm{Hg}$, respiratory rate $18 /$ minute, bilaterally symmetric chest movement with normal vesicular breath sounds, central cyanosis with Grade 3 clubbing (parrot beak appearance) (Figure 1 and 2) with plethoric digits (Figure 3) and plethoric facies (Figure 4) with no peripheral edema. On cardiovascular examination S1 was normal, S2 was single and loud without gallop and a continuous systolic murmur of grade 3 was heard on auscultation of the heart.

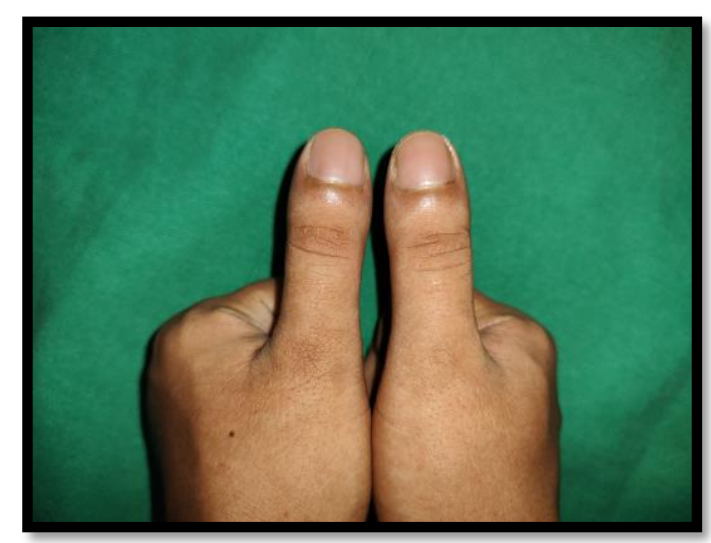

Figure 2: Clubbing.

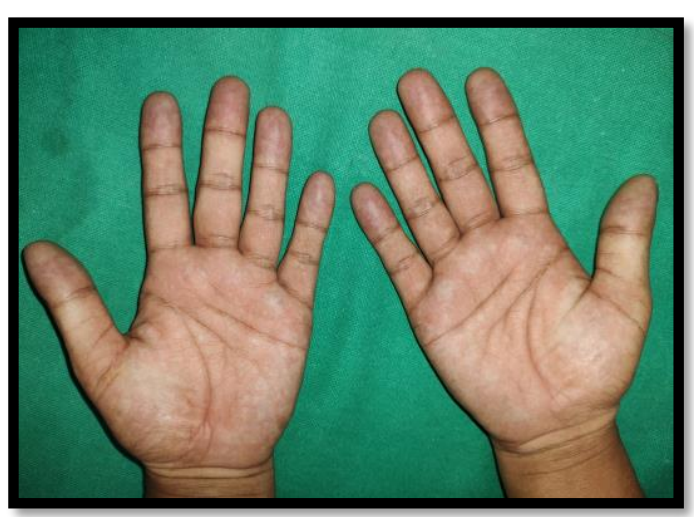

Figure 3: Plethoric digits.

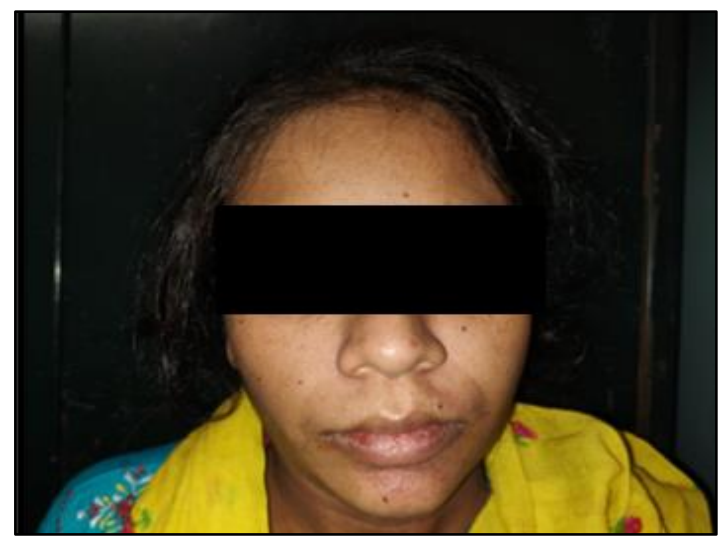

Figure 4: Plethoric faces.

Per abdominal examination showed fundal height 24 weeks, external ballotment present, fetal heart sound were 
localized on doppler and uterus was relaxed. On per vaginal examination external os was closed.

Table 1: Biweekly essential parameters monitoring.

\begin{tabular}{|llll|}
\hline $\begin{array}{l}\text { Weeks since } \\
\text { admission }\end{array}$ & $\begin{array}{l}\text { Hemoglobin } \\
(\mathrm{g} / \mathrm{dl})\end{array}$ & Hematocrit & $\mathrm{SpO}_{2}$ \\
\hline At 24 weeks & 15.1 & $55 \%$ & $86 \%$ \\
\hline At 26 weeks & 14.8 & $53 \%$ & $88 \%$ \\
\hline At 28 weeks & 16.1 & $52 \%$ & $85 \%$ \\
\hline At 30 weeks & 17.2 & $53 \%$ & $86 \%$ \\
\hline At 32 weeks & 16.8 & $48 \%$ & $86 \%$ \\
\hline At 34 weeks & 15.6 & $45 \%$ & $89 \%$ \\
\hline $\begin{array}{l}\text { Post } \\
\text { delivery }\end{array}$ & 15.3 & $42 \%$ & $88 \%$ \\
\hline
\end{tabular}

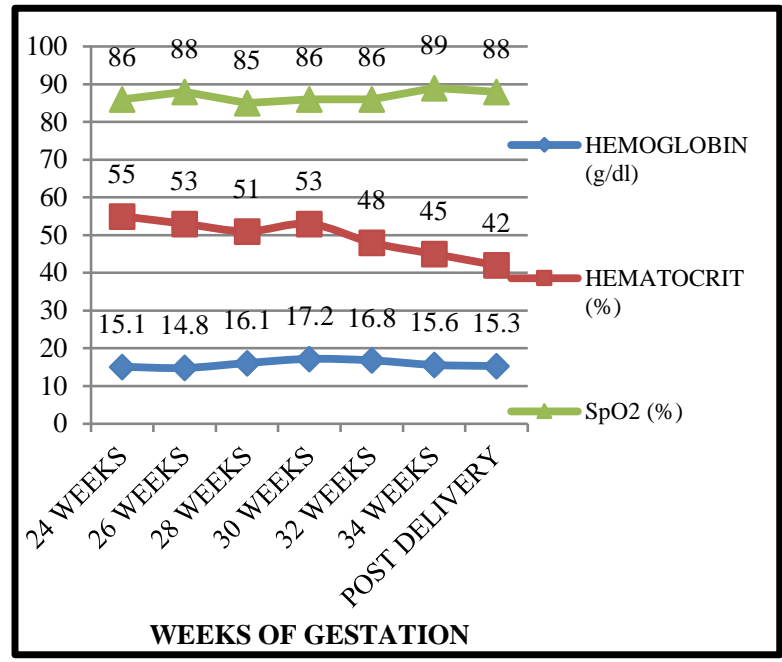

Figure 5: Biweekly parameters trend.

Investigations showed hemoglobin $15.1 \mathrm{~g} / \mathrm{dL}$, hematocrit $55 \%$, WBC count 6200/cc, platelet count 1,80,000/cc. $\mathrm{ABG}$ had $\mathrm{pH}$ of $7.37, \mathrm{pCO} 2$ of $36.6 \mathrm{~mm}$ of $\mathrm{Hg}, \mathrm{cHCO} 3$ of $23 \mathrm{mmol} / \mathrm{L}$, sO2 of $90 \%, \mathrm{Na}+$ of $137 \mathrm{mmol} / \mathrm{L}$ and $\mathrm{K}+$ of $4.0 \mathrm{mmol} / \mathrm{L}$. Ante-natal profile, coagulation profile, other blood chemistry, urine analysis and serum electrolytes were within normal limit. Electrocardiogram showed right ventricular hypertrophy and right axis deviation. Baseline 2D echocardiogram showed a Large non-restrictive malaligned VSD with right to left shunt, presence of overriding of aorta, severe pulmonary and sub-pulmonary stenosis with a right ventricular outflow gradient of 128 $\mathrm{mm}$ of $\mathrm{Hg}$, mild tricuspid regurgitation with SpO2 of $80 \%$. Fetal 2D echocardiogram was also performed which was normal.

Patient's vital parameters were monitored daily including monitoring required for the baby. The tests for maternal surveillance which includes hematocrit and hemoglobin were monitored weekly (Table 1) and values are depicted
(Figure 5). Fetal surveillance tests which included USG obstetric doppler were performed every 2 weeks from 28 weeks till 32 weeks and then weekly from 32 weeks onwards to check for fetal compromise. All the obstetric doppler parameters were normal without values suggestive of fetal compromise although a 2 weeks gestational lag was consistent throughout the pregnancy between gestational age by date and by scan, without any obstetric doppler changes. The last obstetric doppler performed at 35 weeks showed a gestational age on scan of 33 weeks with cephalic presentation, posterior placenta, adequate liquor and expected baby weight of $2.140 \mathrm{~kg}$. The obstetric doppler was normal.

Cardiology and cardio-thoracic surgeon opinions were sought regularly with frequent cardiac 2D echogram studies to check for hemodynamic changes in the heart. Subsequent 2D echocardiogram performed at 28 weeks and 34 weeks were identical without any significant changes. Advice given was to give antibiotic prophylaxis to prevent infective endocarditis and institutional delivery. At 35 weeks and 5 days of gestation, patient complained of absent fetal movements for which biophysical profile was done which showed a score of $6 / 8$ with absence of fetal movements. Non-stress test was also performed which showed a non- reassuring pattern. In view of decreased biophysical profile score and non-reassuring non-stress test decision to do category 2 caesarean section was taken. Patient had already received 2 doses of Injection Betamethasone 12mg, 24 hours apart at 32 weeks of gestation for fetal lung maturity. Preoperatively infective endocarditis prophylaxis was given and also central line was put by the anesthetist for fluid monitoring.

Cesarean section was performed under general anesthesia after obtaining a written, informed and documented consent explaining the high risk. The anesthetic drugs used were injection Etomidate and injection Succinylcholine for induction. For maintenance, oxygen, Sevoflurane and injection Vecuronium was used. The baby had intraoperatively two tight loops of cord around neck, delivered by vertex presentation, cried immediately after birth with 1 minute APGAR score of 9/10 and weighed 1.8 kilogram. The rest of the Caesarean Section was uneventful. Baby was shifted to neonatal intensive care unit due to low birth weight. Patient was extubated successfully and shifted to Intensive care unit for monitoring. Patient was kept in the ICU for 48 hours and on 3rd day shifted to the post-partum ward. She was given intravenous antibiotics for 7 days and restricted intravenous fluids were given in the immediate postoperative period by CVP monitoring. Cardiac opinion was sought post-delivery and 2D echocardiogram was consistent with baseline scan. Hemoglobin and hematocrit monitoring was also performed post delivery which were $15.3 \mathrm{~g} / \mathrm{dl}$ and $42 \%$, respectively.

Baby was screened for congenital anomalies and was found to be normal. Post operative course was uneventful. She was mobilized early and was given elastic stockings 
because of the higher risk of thromboembolic events in her. Patient discharged on day 10 of surgery. Patient was asked to follow up in cardiology and cardio-vasculothoracic surgery OPD after 6 weeks or earlier in presence of any symptoms. Risks of next pregnancy were well explained to husband and were advised to use barrier method for contraception.

\section{DISCUSSION}

ToF is a cyanotic heart disease, which increases the deoxygenated systemic blood due to the right to left shunt. Increase in this is reflected by decreased $\mathrm{SpO} 2$ and a compensatory increase in hemoglobin, hyper viscosity of blood leading to subsequent thrombotic events and chronic respiratory alkalosis. ${ }^{7}$ ToF in pregnancy possess a risk of cardiac decompensation as they are unable to meet the additional demands because of physiological changes of pregnancy and parturition. The various cardiac complications known in these patients includes progressive dilatation of the right ventricle and ventricular failure, thromboembolism, atrial and ventricular arrhythmias, progressive aortic root dilatation and endocarditis. The commonest obstetric maternal complications include increased risk of spontaneous abortions, preterm births and postpartum hemorrhages. The commonest fetal outcomes include low birth weight, intrauterine growth restriction and still births.

Patients who have undergone corrective surgery the physiological cardiovascular changes of pregnancy may unmask residual or recurrent ToF and who have been asymptomatic throughout their life after ToF repair. Women with uncorrected $\mathrm{ToF}$ are in a precariously balanced state as fall in peripheral vascular resistance leads to hypotension and volume overload is poorly tolerated in these patients. These women due to hemodynamic changes specially become vulnerable to decompensation during the later months of pregnancy and postpartum when marked peak in the hemodynamic changes occur. Parturition is the most critical time as the blood loss associated with the process may induce hypotension and eventually the right to left shunt making condition worse.

Presbitero et al in his study demonstrated that the most important risk factor for adverse fetal outcome in cyanotic patients was directly related to the degree of cyanosis. ${ }^{8}$ These authors suggested that an arterial oxygen saturation $>85 \%$ and a hemoglobin concentration $<18 \mathrm{~g} / \mathrm{dl}$ were more likely to result in live birth, as compared to this hemoglobin concentrations $>20 \mathrm{~g} / \mathrm{dl}$ were associated with poor fetal outcome. With increasing maternal hypoxia, the percentage of live-born infants fall and when hypoxemia is intense enough to stimulate a rise in hematocrit above $65 \%$, pregnancy wastage is virtually $100 \% .^{9,10}$ Patients with ToF have an increased risk of fetal loss, and their babies are more likely to have congenital anomalies than in the general population and this mandates a need of performing fetal $2 \mathrm{D}$ echocardiogram as was done in our case. The incidence of cardiac defects in infants of ToF patients ranges from 3 to $17 \% .^{11}$

Patients should be informed that reparative surgeries for cardi $\neg$ ac anomalies are not recommended during pregnancy. Vaginal birth is the preferred mode of delivery in women with ToF. Caesarean section is reserved for only for obstetrical indications. ${ }^{12}$ This is because blood loss is lesser in vaginal delivery (400-500 cc) compared with 800$1000 \mathrm{cc}$ in caesarean section and use of anesthetic drugs may further aggravate the hypotension. In our patient, caesarean was done for fetal indication. Uterotonics like oxytocin and ergometrine have unpredictable effects on the hemodynamic status and should be avoided in ToF patients. Infective endocarditis prophylaxis is recommended, which was given in our patient. Both general and regional anesthesia have been employed successfully in parturient with ToF. Some authors probably prefer general anesthesia technique as endotra $\neg$ cheal intubation provides airway protection, eliminates work of breathing and reduces oxygen consumption as was preferred in our case. ${ }^{13}$ Approximately $15 \%$ of patients have a genetic cause for ToF which is deletion of the short arm of chromosome 22. There is a $50 \%$ probability of transmission to offspring and this warrants the presence of a senior pediatrician at delivery as the infant has a risk of apnea and may require neonatal resuscitation. ${ }^{14}$

\section{CONCLUSION}

Our case suggests that pregnancy in a woman with uncorrected ToF carries substantial risks for fetus and mother and favorable outcome is feasible only under close liaison of a multi-disciplinary team involving obstetrician, cardiologist, cardiac surgeons, anesthetist and neonatologist. Close observation and continuous hemodynamic monitoring are mandatory during the delivery and up to one week postpartum but in spite of appropriate medical care these cases still remain an important cause of maternal morbidity and mortality. Pregnancies are to be avoided in conditions of uncorrected Tetralogy of Fallot but early cardiac screening in symptomatic antenatal patients by $2 \mathrm{D}$ echocardiograms and earliest cardiac opinion should be sought as was done in our patient.

\section{ACKNOWLEDGEMENTS}

We would like to appreciate the medical staff of the cardiology, anaesthesia and neonatal department of LTMMC and LTMGH Hospital, Sion, Mumbai who played an invaluable role in management of this patient.

\author{
Funding: No funding sources \\ Conflict of interest: None declared \\ Ethical approval: Not required
}




\section{REFERENCES}

1. van der Linde D, Konings EEM, Slager MA, Witsenburg M, Helbing WA, Johanna JM. Takkenberg et al. Birth Prevalence of congenital heart disease worldwide: a systematic review and metaanalysis. J Am Coll Cardiol. 2011;58(21):2241-7.

2. Elyakam U. Pregnancy and cardiovascu $\neg$ lar disease. In: Braunwald E, Zipes DP, Libby P, eds. Heart disease: A textbook of c cardio ᄀvascular medicine. 6th ed. 2001;2172-7.

3. McAnulty JH, Metcalfe J, Ueland K. Heart disease and pregnancy. In: Hurst's the heart. Fus $\neg$ ter V.11th ed.

4. Eisner RF, Nieberg RK, Berek JS, Sinto R, Nasution SA. Pregnan $\neg$ cy in a woman with uncorrected tetralo $\neg$ gy of fallot. Acta Med Indones. 2009;41:81-6.

5. Adamson D, Dhanjal M, Nelson-Piercy C. Heart disease in pregnancy. Oxford: Oxford Specialist Handbooks in Cardiology. 2011.

6. Veldtman GR, Connolly HM, Grogan M, Ammash NM, Varnes CA. Outcomes of pregnancy in women with tetralogy of fal $\neg$ lot. J Am Coll Cardiol. 2004;44:174-80.

7. Sankaran VG, Brown DW. Congenital heart disease. In: Lilly LS, eds. Pathophysiology of Heart Disease. 4th ed. Baltimore: Lippincott Williams \& Wilkins. 2007: 390-3.
8. Presbitero P, Demarie D, Aruta E. Results of total correction of tetralogy of Fallot performed in adults. Ann Thorac Surg. 1988;46(3):297-301.

9. Cunnigham FG. Cardiovascular disease. In: Rouse D, Rainey B, Spong C, Wendel GD, eds. Williams Obstetrics. 23rd ed. New York: McGraw-Hill Companies. 2005;963-70.

10. Warnes CA. Cyanotic congenital heart disease. In: Oakley C, Warnes CA, eds. Heart Disease in Pregnancy. 2nd ed. Massachusetts: Blackwell Publishing. 2007;43-7.

11. Uebing A, Steer PJ, Yentis SM, Gatzoulis MA. Pregnancy and congenital heart disease. Br Med J. 2006;332:401-6.

12. Oakley C. Expert consensus document on management of cardiovascular diseases during pregnancy. Eur Heart J. 2003;24:762-5.

13. Morgan GE. Obstetric anesthesia. In: Morgan GE, Mikhail MS, Murray MJ, eds. Clinical Anesthesiology. 4th ed. New York: Lange Medical Books/McGraw-Hill. 2006;902-12.

14. Payne RM, Johnson MC, Grant JW. Toward a molecular understanding of congenital heart disease. Circulat. 1995;91:494-504.

Cite this article as: Nimbkar AR, Panchbudhe SA, Deshmukh PY, Nayak AH. Successful maternal and fetal outcome in an uncorrected case of tetralogy of fallot. Int J Reprod Contracept Obstet Gynecol 2021;10:4561-5. 